\title{
Encouraging and Advancing the Reconversion of Rubber Plantations: Developing Incentives Using a Combined Market and Government Payment System
}

Weiguo Liu ( $\sim$ liuweiguo110@gmail.com )

Northwest A\&F University https://orcid.org/0000-0001-8176-2522

Jiaqi Zhang

Xishuangbanna Tropical Botanical Garden

Yan Yan

Northwest Agriculture and Forestry University

Philip Beckschäfer

Northwest German Forest Research Institute: Nordwestdeutsche Forstliche Versuchsanstalt

Christoph Kleinn

University of Göttingen Faculty of Forest Sciences and Forest Ecology: Georg-August-Universitat Gottingen Fakultat fur Forstwissenschaften und Waldokologie

Gbadamassi G.O. Dossa

Xishuangbanna Tropical Botanical Garden

Jianjun Huai

Northwest Agriculture and Forestry University

Liang Song

Xishuangbanna Tropical Botanical Garden

\section{Research Article}

Keywords: Xishuangbanna, rubber plantation reconversion, compensatory payment, market-priced ecosystem services, carbon sequestration, tropical rain forest

Posted Date: June 3rd, 2021

DOl: https://doi.org/10.21203/rs.3.rs-564065/v1

License: (c) (i) This work is licensed under a Creative Commons Attribution 4.0 International License. Read Full License 
1 Encouraging and Advancing the Reconversion of Rubber Plantations:

2 Developing Incentives Using a Combined Market and Government Payment

3 System

4 Weiguo Liu ${ }^{1,2}$, Jiaqi Zhang ${ }^{3}$, Yan Yan ${ }^{1,2}$, Philip Beckschäfer ${ }^{4,5}$, Christoph Kleinn ${ }^{4}$, Gbadamassi

5 G.O. Dossa ${ }^{6,7}$, Jianjun Huai ${ }^{8}$, Liang Song ${ }^{6,7^{*}}$

$6{ }^{1}$ Center for Ecological Forecasting and Global Change, College of Forestry, Northwest

7 Agriculture and Forestry University, Yangling, Shaanxi 712100, China

$8{ }^{2}$ Qinling National Forest Ecosystem Research Station, Yangling, Shaanxi 712100, China

$9{ }^{3}$ Center for Integrative Conservation, Xishuangbanna Tropical Botanical Garden, Chinese

10 Academy of Sciences, Menglun 666303, Yunnan, China

$11{ }^{4}$ University of Göttingen, Forest Inventory and Remote Sensing, Büsgenweg 5, 37077

12 Göttingen, Germany

$13{ }^{5}$ Current affiliation: Northwest German Forest Research Institute, Grätzelstr 2, 37079 Göttingen,

14 Germany

$15{ }^{6}$ CAS Key Laboratory of Tropical Forest Ecology, Xishuangbanna Tropical Botanical Garden,

16 Chinese Academy of Sciences, Menglun 666303, Yunnan, China

$17{ }^{7}$ Center of Plant Ecology, Core Botanical Gardens, Chinese Academy of Sciences, Menglun

18 666303, Yunnan, China

$19{ }^{8}$ College of Economics \& Management, Northwest Agriculture and Forestry University,

20 Yangling, Shaanxi 712100, China 
21 Abstract: In various regions in Southeast Asia, over the past decades, natural tropical forests

22 have rapidly been converted into monoculture plantations of rubber (Hevea brasiliensis), a

23 consequence of the rubber boom. With the goal of slowing the ecologically and environmentally

24 detrimental conversion of forests to rubber plantations and to encourage the reconversion of

25 rubber plantations back to close-to-nature rainforests, we developed a theoretical combined

26 market and government payment system. To evaluate the potential impacts of such system, we

27 carried out a simulation study plus sensitivity analyses, using the latest land-use data from

28 Xishuangbanna, Southwest China. The results of this simulation suggest that the payment system

29 may make the annual reconversion rate develop from 9,009 ha to 4,610 ha over the modeled

30 period from 2021 to 2050 , so that the total reconversion area by 2050 would sum up to 197,902

31 ha. The total net present value (NPV) of compensatory payments for the whole period, in this

32 case, would sum up to US\$3.19 billion. The total carbon sequestration benefit resulting from the

33 replacement of rubber plantations would be 11.37 million tons of carbon (tC) over the modelled

34 period, translating into a cost of US\$280.44 per tC. Sensitivity analyses revealed that higher

35 variations in rubber prices cause more difficulty in determining compensatory payment. Of

36 course, changes in a number of factors may lead to a reduction of the total NPV of compensatory

37 payments, including increases in the carbon price or traditional medicine price, increases in the

38 discount rate, and decreases to the rubber price and the targeted final reconversion rate. The area-

39 specific compensatory payments $(\$ 11,154-\$ 16,106 /$ ha) and area-specific carbon sequestration

$40 \quad(46.39-57.45 \mathrm{tC} / \mathrm{ha}$ ) would then increase linearly as the targeted final reconversion rate

41 increases. This new integrated payment system has the potential to contribute to restoring

42 rainforest in rubber monoculture-dominated landscape. 
43 Keywords: Xishuangbanna, rubber plantation reconversion, compensatory payment, market-

44 priced ecosystem services, carbon sequestration, tropical rain forest

\section{Introduction}

Global rubber demand has been rising for decades: more than $52,392 \mathrm{~km}^{2}$ of tropical

forests were replaced by rubber (Hevea brasiliensis) plantations across mainland Southeast Asia

49 between 2001 and 2014 (Hurni and Fox, 2018). One of the areas formerly most densely

50 dominated by natural forests, Xishuangbanna, which is located in Southwest China and neighbor

51 to Laos and Myanmar, experienced a tremendous forest cover loss, with forest area decreasing

52 from $71 \%$ in 2002 to $52 \%$ in 2018 (Zhang et al., 2019). Most of these forests were converted to

53 rubber plantations, whose proportion of coverage doubled from $11 \%$ to $21 \%$ during the same

54 period (Zhang et al., 2019). Starting from the valleys, rubber plantations expanded into marginal

55 lands characterized by higher elevations, steeper slopes, and even encroached into protected

56 areas (Chen et al., 2016; Sarathchandra et al., 2018). While rubber plantations provide a major

57 contribution to poverty reduction and local economic development (Lan et al., 2017), their

58 dramatic spread at the expense of natural forests has caused many unfavorable ecological and

59 environmental consequences, such as loss of biodiversity, increased carbon emissions, pollution

60 of water and landscape by pesticides, and soil erosion (Li et al., 2007; Hu et al., 2008; Tan et al.,

61 2011; Chen et al., 2016; Lan et al., 2017). How to integrate ecological protection into natural

62 rubber latex production systems and how to foster ecosystem services have become key issues in

63 achieving both regional economic growth and sustainable development (Wang et al., 2020). 
To date, both scholars and decision-makers have recognized the importance of

reconverting rubber plantations back into close-to-nature forests to reconcile the impacts of human development on nature (Warren-Thomas et al., 2018). Various measures have been discussed to foster these reconversion efforts, including the establishment of protected areas, the implementation of restrictive regulations, and the restriction of natural rubber prices (Yi et al., 2014b; Stevanovic et al., 2017; Smajgl et al., 2015). Some studies have suggested that payments for ecosystem services (PES) from the government may promote forest reconversion while reducing deforestation, especially in the downturn of the rubber market after 2011 (Yi et al., 2014a; Zhang et al., 2015). However, PES solely from government can be problematic because they usually fail to outcompete the profit that smallholders expect to gain from rubber production. PES also tend to increase the financial pressure on local governments (Smajgl et al., 2015). Beyond governmental offerings, a market-based solution was also proposed as a potentially successful alternative (Yi et al., 2014a). For instance, some ecosystem services have a market-price and are traded on a regular basis, such as carbon sequestration, and food and timber production (Bateman et al., 2013, Bryan et al., 2018). An economic valuation of market-priced ecosystem services may reveal ways to alleviate the fiscal burden on the government and provide an incentive for both forest preservation and reconversion, especially of the less productive rubber plantations back into forests (Bateman et al., 2013; Alhassan et al., 2019).

In this study, the overall objective is to support the reconversion of rubber plantations into close-to-nature forests so that the ecological services of the landscape are improved. From a technical perspective, the major objectives are (1) to devise a combined market and government payment system, (2) to simulate its implementation in Xishuangbanna, including a prediction of the necessary amount of compensatory payments by the government, and assessing the 
87 sensitivities of various factors that may affect the rubber reconversion rate and the required government payments.

89 Materials and Methods

The first subsection of this section, "Study Area", presents background information about

91 Xishuangbanna and the artificial rainforest as the target ecosystem. The second subsection

92 "Land-Use Classification and Stand Age of Rubber Plantation" introduces the methods used to 93 determine the area and age of rubber plantations. In the subsection "Model Development", we 94 specify the structure of the combined market and government payment system. We then apply

95 the system to Xishuangbanna; models for ecosystem services and opportunity costs can be found 96 in the subsection "Model Simulation and Parameter Setting". In the last section, we define the 97 baseline and sensitivity analyses.

Study Area

Xishuangbanna Dai Autonomous Prefecture $\left(21^{\circ} 08^{\prime} \mathrm{N}-22^{\circ} 36^{\prime} \mathrm{N}, 99^{\circ} 56^{\prime} \mathrm{N}-101^{\circ} 50^{\prime} \mathrm{N}\right)$ is located in Yunnan Province, southwest China, and borders of Laos and Myanmar (Fig. 1). Of its

101 area of $19,200 \mathrm{~km}^{2}, 52 \%$ is covered by natural forest, i.e. tropical seasonal rainforest, montane 102 rainforest, and evergreen broad-leaved forest (Zhang et al., 2019). This region is home to a high 103 level of biodiversity, with $18 \%$ of the plant species and $20 \%$ of vertebrate species found in China 104 (Pei, 2010). The elevation ranges from $475 \mathrm{~m}$ to 2,428 $\mathrm{m}$ above sea level (a.s.1.). The annual 105 average temperature over the past four decades is $21.7^{\circ} \mathrm{C}$ and the annual average precipitation is 106 1,480 mm (Liu et al., 2014). The fast expansion of cash crops, such as rubber (H. brasiliensis) 107 and tea (Camellia sinensis) that took place during the last decades reduced natural forest area 
108 dramatically and induced a decrease in biodiversity. The area of rubber plantations also doubled 109 while forest patch size decreased 10-fold from 2002 to 2014 (Zhang et al., 2019).

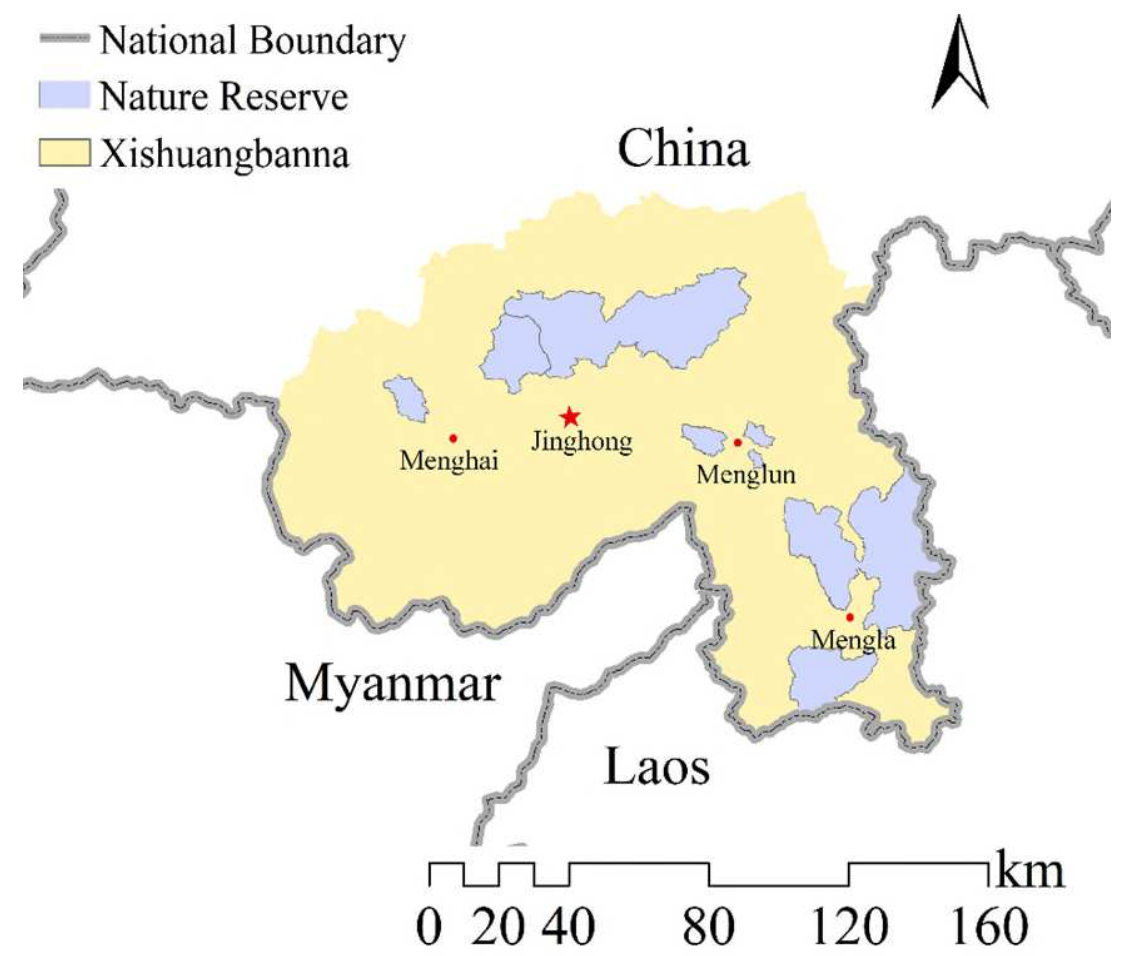

114 rubber plantations into artificial rainforests, which are meant to resemble natural rainforests and

115 support the provision of ecosystem services. Considering that an intensively managed rubber

116 plantation cannot be converted into a natural rainforest in the short term, we chose the artificial

117 rainforest as the target ecosystem for the reconverted lands. To assess the benefits resulting from

118 this conversion, we collected data from an experimental site at the Xishuangbanna Tropical

119 Botanical Garden in Menglun, China. The site was created to explore ways to reconvert tropical 
120 rainforests from rubber plantations (Tang et al., 2003). An artificial rainforest (1.42 ha) was

121 established on this site in 1960 (see details in the supporting information) in which a permanent

122 observation plot $(30 \mathrm{~m} \times 30 \mathrm{~m})$ was set up in 2008 by the Xishuangbanna Tropical Rainforest

123 Ecosystem Station. In total, 48 plant species (40 from the tree layer and 8 from the herbaceous

124 layer) were recorded in the observation plot until 2020 and several studies have shown that, in

125 comparison to rubber plantations, artificial rainforests can support higher levels of biodiversity

126 (Deng et al., 2012), increase carbon sequestration (Tang et al., 2003), improve microclimatic

127 environment (Liu and Duan, 1997), regulate soil temperature (Liu and Li, 1997), and mitigate

128 soil erosion (Deng et al., 2012).

\section{Land-Use Classification and Stand Age of Rubber Plantation}

A 2018 land-use map by Zhang et al. (2019) depicts Xishuangbanna's land-use pattern in 2018 was used for our projection. We assumed no changes to land-use occurred between 2018 and 2020. The land-use map for 2018 is based on 32 Landsat images that were classified using a nearest-neighbor-object-based phenology approach (Zhai et al., 2018). The overall classification accuracy of the map is $96.2 \%$ and it contains six land cover types: natural forests (> 30\% tree cover, including all-natural forest types and bamboo), shrublands $(<30 \%$ tree cover, including young secondary forest and degraded forest areas), rubber plantations, tea plantations, farmlands (including paddy rice, vegetables, sugar cane, and banana plantations), and other land-uses (including urban and industrial areas, quarries, roads, water bodies, and barren land).

The age of the rubber plantation was a critical piece of information, which we used to simulate rubber yield and correlated ecosystem services provided by the plantation. We used data from Beckschäfer (2017), who mapped the year of plantation establishment during 1988 to 2015 using a very dense time series of Landsat TM and ETM+ data. Map validation revealed the root 
143 mean square error of the mapped predictions to be 2.5 years. The ages of all the rubber

144 plantations were increased by 5 to project the map into the year 2020 . We assumed the rubber

145 stand has a 25-year rotation length.

146 Model Development

147 For this paper, we developed a combined market and government payment system (Fig.

148 2). In this system, farmers that reconvert rubber plantation area into the target ecosystem, an

149 artificial rainforest, receive revenues from payments for market-priced ecosystem services $\left(E S_{a}\right)$

150 and compensatory payments from the government $(S)$. The system is based on a raster map in

151 which rubber plantations are represented as pixels $(30 \mathrm{~m} \times 30 \mathrm{~m}$ in this study). A rubber

152 plantation area (i.e., a pixel) needs to satisfy three conditions before being qualified for receiving

153 compensation payments. The first condition is that the rubber plantation area should be on the

154 edge of a rubber plantation patch. However, the landowners' willingness of reconversion cannot

155 be predetermined. Thus, we assumed that the reconversion decision is a random process and

156 generated by a binomial possibility confined by the targeted final reconversion rate. The second

157 condition is that the decision should be "Yes". Once the second condition is satisfied, the third

158 condition is that this decision to reconvert would result in more profit for the landowner. 


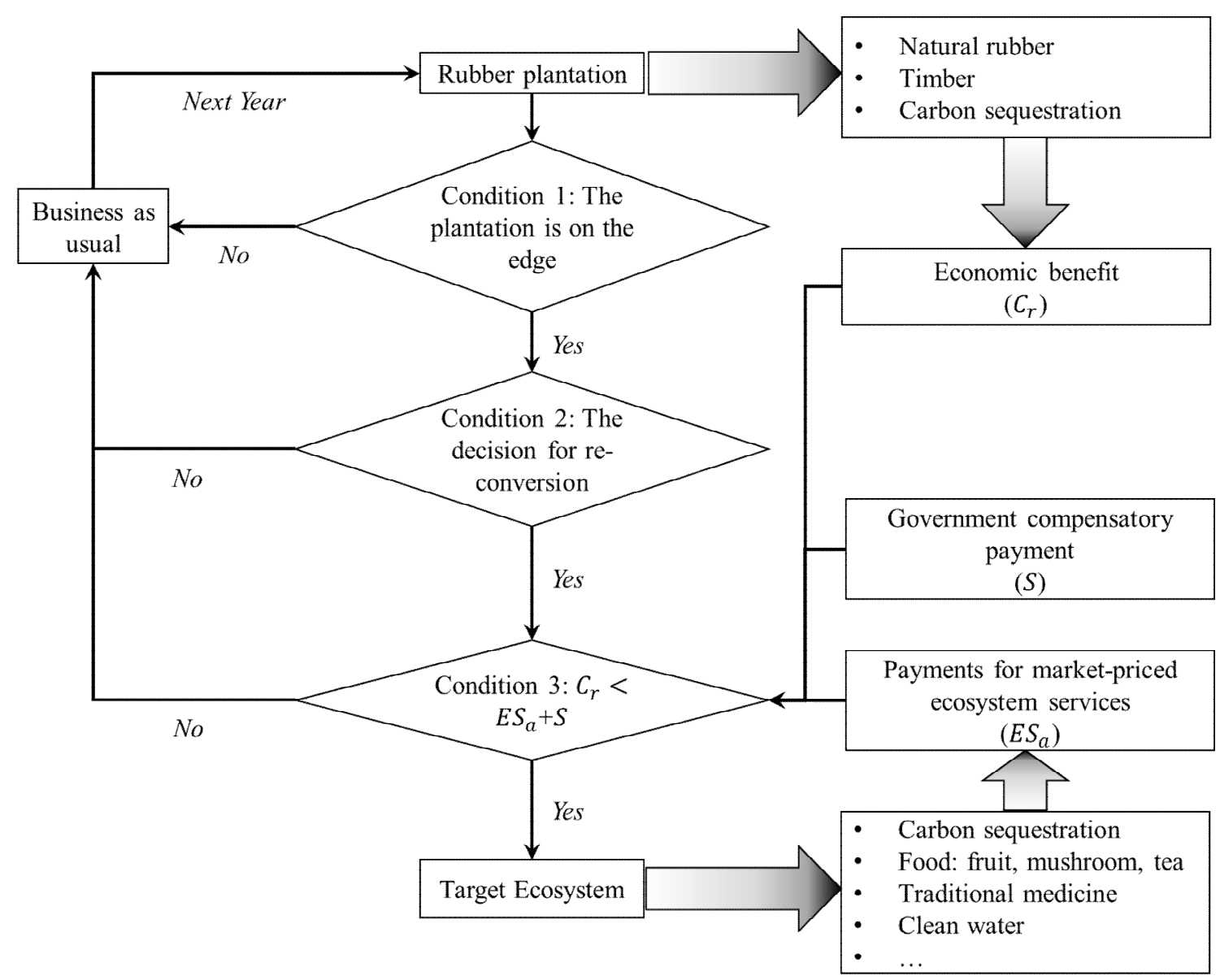

Fig. 2. The framework of the combined market and government payment system

161 patches and, hence, avoid management difficulties from the unnecessary fragmentation of rubber 162 plantations (Zhang et al., 2019). If the plantation is on an edge, the pixel has at least one side 163 adjacent to a different land-use type. After the plantation pixel is confirmed to be on an edge, the 164 decision to reconvert the rubber plantation ("Yes" or "No") is randomly generated based on the 165 binomial possibility $b_{i}$. The decision is simulated by random generation because all the rubber 166 farms have possibility to reconvert their plantations and the decision is hard to predict. The 167 binomial possibility of reconversion in year $i$ is determined as follows:

$$
b_{i}=\frac{B}{m} \cdot \frac{N_{\text {total }}}{N_{\text {edge }}}
$$


169 where $b_{i}$ is the binomial possibility of reconversion in year $i$ and $B$ is the targeted reconversion 170 rate at the end of the projection. The term $m$ is a number used to enforce an even reconversion

171 and is adjusted in the system to ensure that the final reconversion rate is close to $B . N_{\text {edge }}$ and

$172 N_{\text {total }}$ are the pixel number on the edge of rubber plantation patches and the total pixel number

173 of rubber plantations, respectively. The final reconversion rate is the ratio of total reconverted

174 rubber plantation in the projected period to the initial area of rubber plantation. The annual

175 reconversion rate in year $i$ is defined as the ratio between the reconverted rubber plantations and 176 the total rubber plantations in year $i$.

177 To satisfy the third condition, $C_{r}$ represents the opportunity cost of a rubber plantation, 178 and $E S_{a}$ is the economic benefit of market-priced ecosystem services from a target ecosystem.

179 The plantation is eligible for reconversion if:

$$
C_{r}<E S_{a}+S, \quad(2)
$$

181 where $C_{r}$ and $E S_{a}$ are calculated in 25-year discounted net present value (NPV) with a discount 182 rate $r . S$ is the compensatory payment from government and is also calculated in NPV (Warren183 Thomas et al., 2018):

$$
C_{r}=\sum_{n=25}^{i} \frac{c_{i}}{(1+r)^{i}}
$$

$$
E S_{a}=\sum_{n=25}^{i} \frac{e s_{i}}{(1+r)^{i}}
$$

$$
\mathrm{S}=\sum_{n=25}^{i} \frac{s_{i}}{(1+r)^{i}}
$$


187 where $c_{i}$ is the opportunity cost of the rubber plantation reconversion from rubber production,

188 timber, and carbon sequestration in year $i, e s_{i}$ is the economic benefit of market-priced

189 ecosystem services from the target ecosystem in year $i$, and $s_{i}$ is the government compensatory

190 payment in year $i$; $r$ is the discount rate. It is assumed that the incentive of the rubber plantation

191 reconversion will increase with increases in compensatory payments. Therefore, the government

192 compensatory payment is decided as follows:

$$
s_{i}=c_{i}+c_{i} b_{i}-e s_{i}
$$

Model Simulation and Parameter Setting

To calculate the opportunity cost of a rubber plantation reconversion and the economic

197 accumulation, carbon sequestration, production of rubber, fruit, timber, and traditional medicine 198 all need to be simulated.

The aboveground biomass accumulation (tC/ha) of rubber plantations and artificial rainforests was simulated using logistic models based on continuous measurements (Tang et al.,

201 2003). The belowground biomass was assumed to be $25 \%$ of the aboveground biomass (Warren202 Thomas et al., 2018). The rubber yield curve was generated from the long-term record of the 203 Dongfeng State Farm (Zhang et al., 2015). Because rubber plantations usually exhibit a high 204 level of production when located below $800 \mathrm{~m}$ a.s.l. (Song and Zhang, 2010, Min et al., 2017), 205 and because $900 \mathrm{~m}$ a.s.l. is the accepted boundary between tropical seasonal rainforest and 206 montane rainforest, we adjusted different parameter settings for forests and plantations 207 distributed below $600 \mathrm{~m}$ a.s.1., 600-800 m a.s.1., 800-900m a.s.1., and above $900 \mathrm{~m}$ a.s.1. (Song 208 and Zhang, 2010, Min et al., 2017). The production of traditional medicines and timber was 209 derived from the aboveground biomass. Fruit yield, as well as the prices of production and costs 
210 for establishment and management were empirical values retrieved from previously published 211 papers.

The models and the parameters are specified in detail in the Supporting Information. The 213 projected period was 30 years, set from 2021 to 2050.

214 Baseline Definition and Sensitivity Analyses

In this payment system, the compensatory payments are adjusted according to the opportunity cost and economic benefits derived from the market-priced ecosystem services. The

217 system ensures a stable annual reconversion rate of the rubber plantations. The parameter setting

218 for the baseline is specified in the previous two subsections and is listed in Table 1.

The effects of the six named parameters were analyzed in this study, including rubber

220 price, rubber price variation, carbon price, targeted final reconversion rate, traditional medicine

221 price, and discount rate. The highest and lowest rubber prices were set to the highest and lowest

222 price in the last decade $(\$ 4.86 / \mathrm{kg}$ and $\$ 1.56 / \mathrm{kg})$. The rubber price was assumed to follow a

223 normal distribution and allowed to randomly change with high and low derivations. The

224 derivations were the derivation and half derivation of rubber price in the last 10 years 2010

2252019 , respectively (FRED, 2020). The carbon price was set to \$0/tC for the lowest possible

226 price, and $\$ 75.60 / \mathrm{tC}$ for the highest possible price (the highest price is from Korea's Emission

227 Trading Scheme, ICAP, 2019). In the baseline, an aggressive reconversion rate was expected to

228 reduce the area of rubber plantations to the level before 2001 (Zhang et al., 2019). To test the

229 sensitivity of the targeted final reconversion rate, reconversion rates were set from $5 \%$ to $50 \%$ by

$2305 \%$ increments. The discount rate was changed from $1 \%$ to $10 \%$ in the analysis. The supply of

231 traditional medicine could be overwhelming as more rubber plantations were reconverted. To 
232 test the reducing price effect of traditional medicine, we considered a moderate price $(\$ 1.45 / \mathrm{kg})$

233 and a low price $(\$ 0 / \mathrm{kg})$. One thousand simulations were conducted for every case.

Table 1. Definition of the baseline and sensitivity analyses

\begin{tabular}{lll}
\hline Parameter & Baseline & Sensitivity analyses \\
\hline Rubber price $(\$ / \mathrm{kg})$ & 2.47 & High: 4.86 \\
& & Low: 1.56 \\
Rubber price variation $(\$ / \mathrm{kg})$ & $\sim N(2.47,0)$ & High variability: $\sim N(2.47,1.12)$, \\
& & Low variability: $\sim N(2.47,0.56)$ \\
Carbon price $(\$ / \mathrm{tC})$ & 11.37 & Low possible price: 0 \\
& & high possible price: 75.6 \\
Targeted final reconversion & Aggressive: $50 \%$ & $5 \%, 10 \%, 15 \%, 20 \%, 25 \%$, \\
rate in 2050 & & $30 \%, 35 \%, 40 \%, 45 \%, 50 \%$ \\
Traditional medicine price & 2.9 & Moderate price: 1.45 \\
$(\$ / \mathrm{kg})$ & & Low price: 0
\end{tabular}




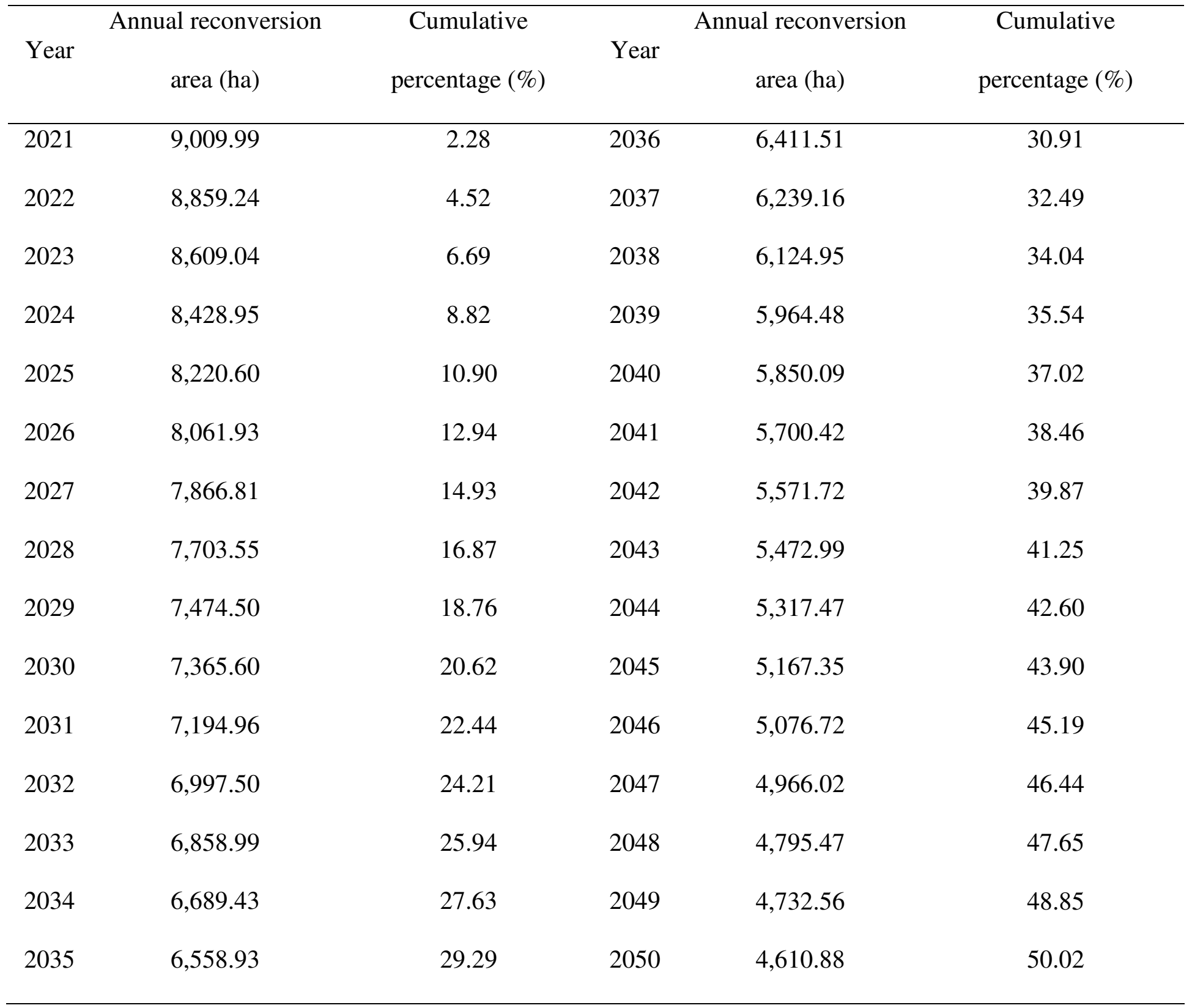

238

239 Results

240 Reconversion Dynamic in the Baseline 
In the baseline, the final reconversion rate of rubber plantation is $50.02 \%$ and a total of

$242197,901.81$ ha of the plantations are reconverted between 2021 and 2050, in contrast to the

$243395,677.9$ ha of rubber plantations in 2020 . About $20.62 \%$ of the initial rubber plantations are

244 reconverted in the first decade, and $16.4 \%$ and $13 \%$ in the following two decades (Table 2). The

245 variance from the random selection of reconversion is negligible, which is less than $0.1 \%$ of the

246 mean.

As the reconversion of rubber plantations progresses, the boundary of the rubber

248 plantations gradually moves from the edge to the center of rubber plantation patches (Fig. 3). As

249 more rubber plantations are reconverted, the small patches in the west and north are occupied by

250 artificial rainforests. The large patches in the south likewise shrunk.
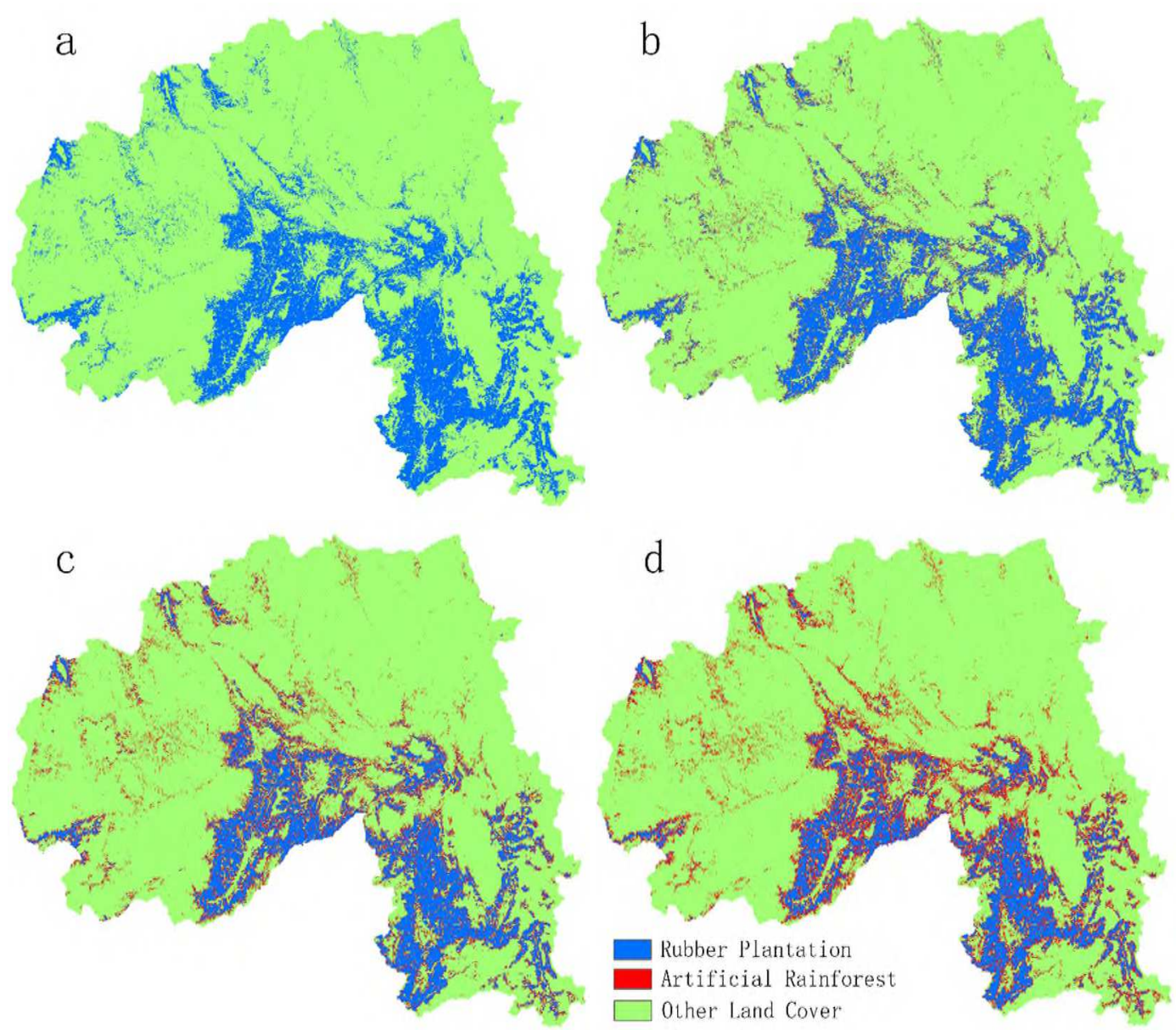

encourage rubber plantation reconversion. When a rubber plantation is reconverted, payments to establish artificial rainforests are higher in the first year, and will remain unchanged in the

256 following years (Fig. 4). The overall NPV of compensation amounts to $\$ 3.19$ billion. The annual 257 compensatory payments constantly increase with the accumulation of previously reconverted

258 plantations. However, the increment of annual payments is reduced over time, from $\$ 33.41$ million in 2021 to $\$ 25.13$ million in 2050 (Fig. 4), where the increment of the annual payments is the compensatory payments for the newly reconverted rubber plantations in the specific year.

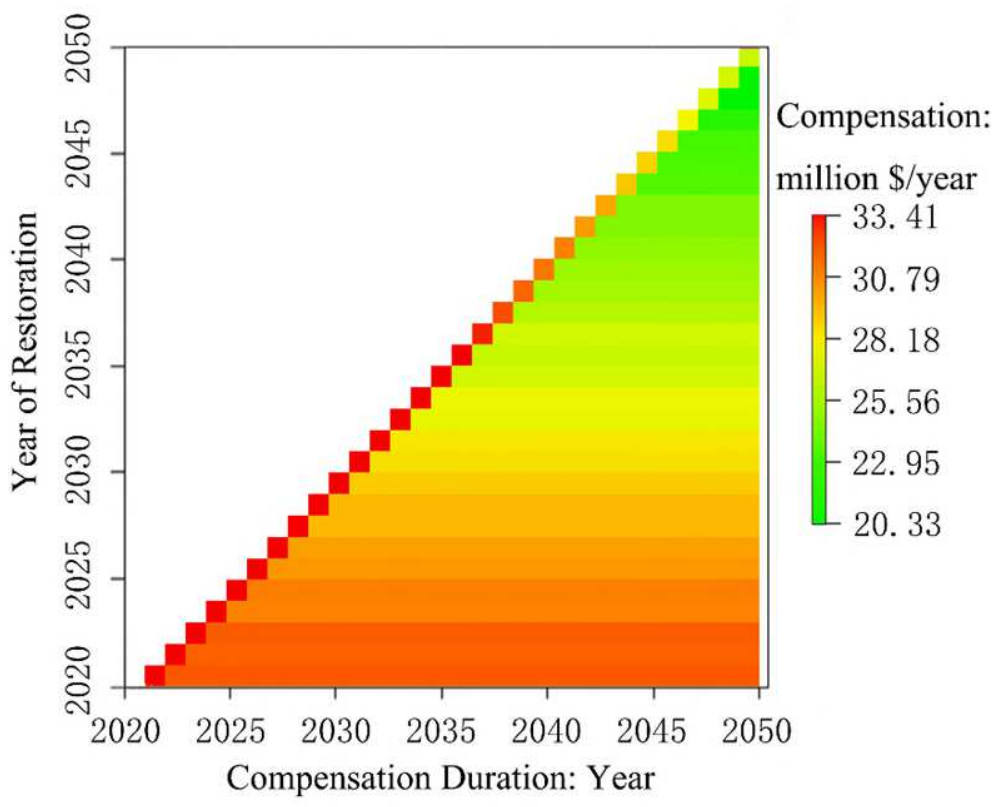

Fig. 4. Annual compensatory payment increments in the projected period, 2021-2050 The benefit derived from total carbon sequestration, defined as the difference in carbon sequestration between artificial rainforests and rubber plantations, is 11.37 million tC (57.39

$264 \mathrm{tC} / \mathrm{ha})$. This benefit comes mainly from the growth of artificial rainforests $(25 \%)$ and the carbon 265 removal (i.e., timber harvest) in old rubber plantations (75\%). The annual benefit of carbon sequestration from the reconversion of a rubber plantation to an artificial rainforest is actually 
267 predicted to be negative in the first decade, and starts to increase after 2027, with a peak in 2037

268 (Fig. 5). The benefit drops shortly and increases steadily thereafter.

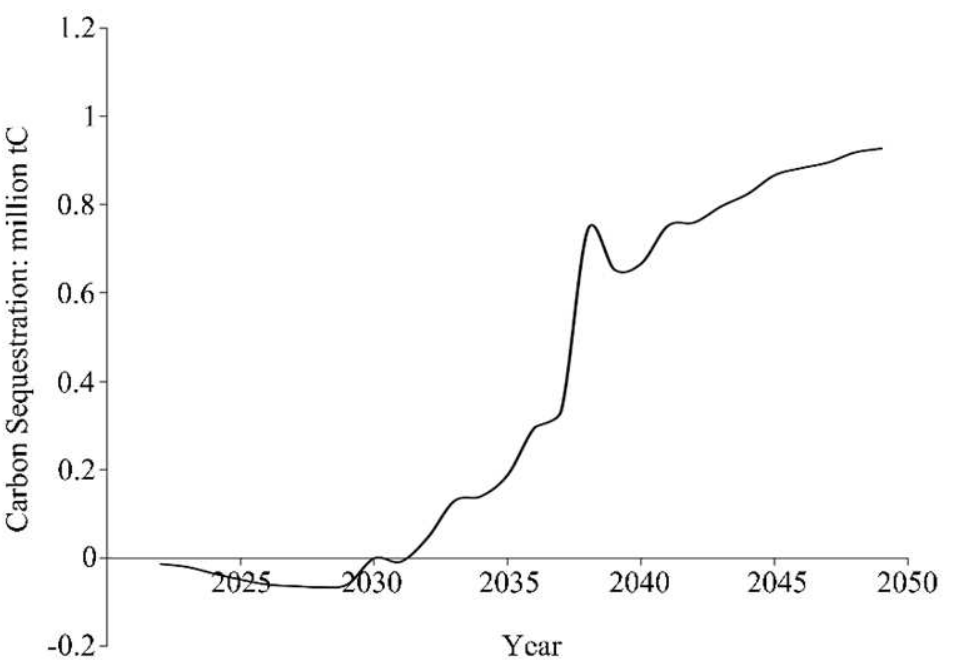

Fig. 5. Annual carbon sequestration in the baseline within the projected period, 2012-2050

271 Sensitivities

The six factors in this study pronouncedly affect the government compensatory payments

273 (Table 3, Fig. 6). The annual payments diminish along with the decrease of rubber price, final

274 reconversion rate, discount rate, and the increase of carbon price and traditional medicine price

275 (Fig. 6). The high rubber price (96.8\% higher than the baseline) can effectively increase the

276 compensatory payments in NPV by $41.7 \%$, and the low rubber price $(36.8 \%$ lower than the

277 baseline) reduced payments in NPV by $16.0 \%$. The random variation of rubber price introduces

278 more uncertainty to the compensatory payments. The high and low rubber price variations result

279 in $2.9 \%$ and $1.8 \%$ deviations of the mean payments ( $0.1 \%$ in the baseline), respectively. A 5.65

280 times increase in carbon price brings down the compensatory payment in NPV by $2.2 \%$. A

281 change in the discount rate from $10 \%$ to $1 \%$ can increase total compensatory payments in NPV 
282 by 3.5 times. The $50 \%$ and $100 \%$ reduction of traditional medicine price can increase total 283 payments in NPV by $6.9 \%$ and $13.8 \%$, respectively.

284 A lower requirement for the targeted final reconversion rate reduces the compensatory 285 payment (Table 4). The NPVs of compensatory payments and carbon sequestration increase 14.5 286 times and 12.4 times from a 5\% targeted final reconversion rate to 50\%, respectively. The area287 specific compensatory payments increase linearly from $\$ 11,154 /$ ha for $5 \%$ to $\$ 16,106 /$ ha for $28850 \%$. None of the factors had a significant effect on carbon sequestration except the targeted 289 final reconversion rate. However, a low reconversion rate brings low carbon sequestration 290 benefits.

Table 3. Effect of the different factors on rubber plantation reconversion

\begin{tabular}{|c|c|c|c|c|c|}
\hline \multirow{3}{*}{ Factors } & \multirow{3}{*}{ Scenarios } & \multirow{3}{*}{ Area: ha } & \multirow{2}{*}{$\begin{array}{l}\text { Carbon } \\
\text { sequestration }\end{array}$} & \multirow{2}{*}{$\begin{array}{l}\text { Cost in net } \\
\text { present value }\end{array}$} & \multirow{2}{*}{$\begin{array}{l}\text { Final } \\
\text { reconversion }\end{array}$} \\
\hline & & & & & \\
\hline & & & (million tC) & (billion \$) & rate $(\%)$ \\
\hline Baseline & & $197,901.81$ & 11.37 & 3.19 & 50.02 \\
\hline \multirow[t]{2}{*}{ Rubber Price } & High & $197,744.90$ & 11.35 & 4.52 & 49.98 \\
\hline & Low & $197,943.80$ & 11.38 & 2.68 & 50.03 \\
\hline \multirow[t]{2}{*}{ Carbon price } & Low price & $197,805.42$ & 11.37 & 3.2 & 49.99 \\
\hline & High price & $197,752.86$ & 11.37 & 3.12 & 49.98 \\
\hline Traditional & Moderate price & $197,935.92$ & 11.37 & 3.41 & 50.02 \\
\hline medicine price & Low price & $197,803.08$ & 11.37 & 3.63 & 49.99 \\
\hline \multirow[t]{2}{*}{ Discount rate } & $1 \%$ & $197,839.08$ & 11.37 & 8.7 & 50.00 \\
\hline & $2 \%$ & $198,021.15$ & 11.37 & 7.46 & 50.05 \\
\hline
\end{tabular}




\begin{tabular}{llllc}
\hline $3 \%$ & $197,905.05$ & 11.38 & 6.42 & 50.02 \\
$4 \%$ & $197,996.40$ & 11.37 & 5.54 & 50.04 \\
$5 \%$ & $197,705.79$ & 11.35 & 4.78 & 49.97 \\
$6 \%$ & $197,722.89$ & 11.36 & 4.16 & 49.97 \\
$7 \%$ & $197,739.18$ & 11.35 & 3.63 & 49.97 \\
$9 \%$ & $197,996.94$ & 11.38 & 2.81 & 50.04 \\
$10 \%$ & $197,889.21$ & 11.37 & 2.48 & 50.01 \\
\hline
\end{tabular}
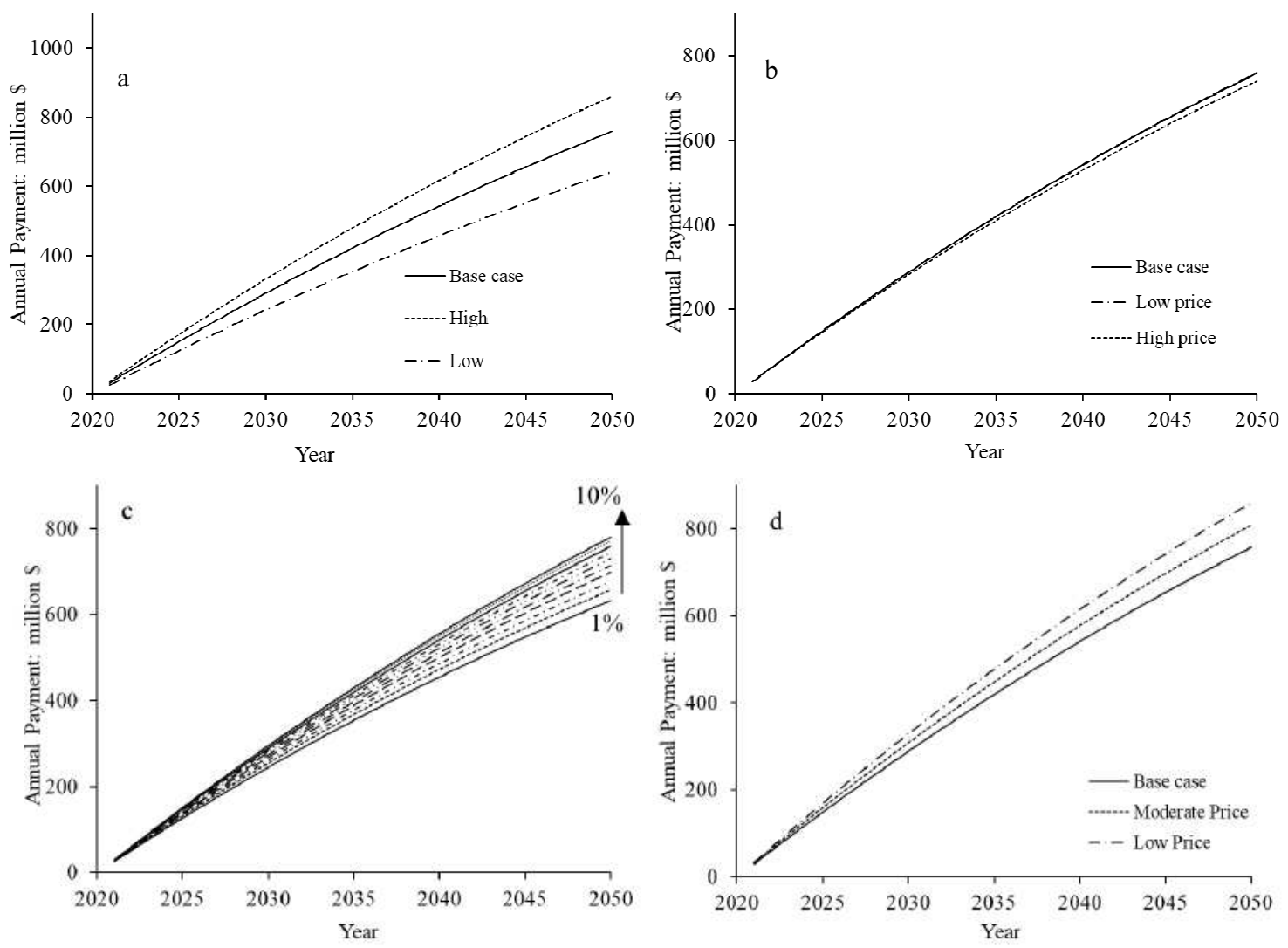
price, c) discount rate and d) traditional medicine price 


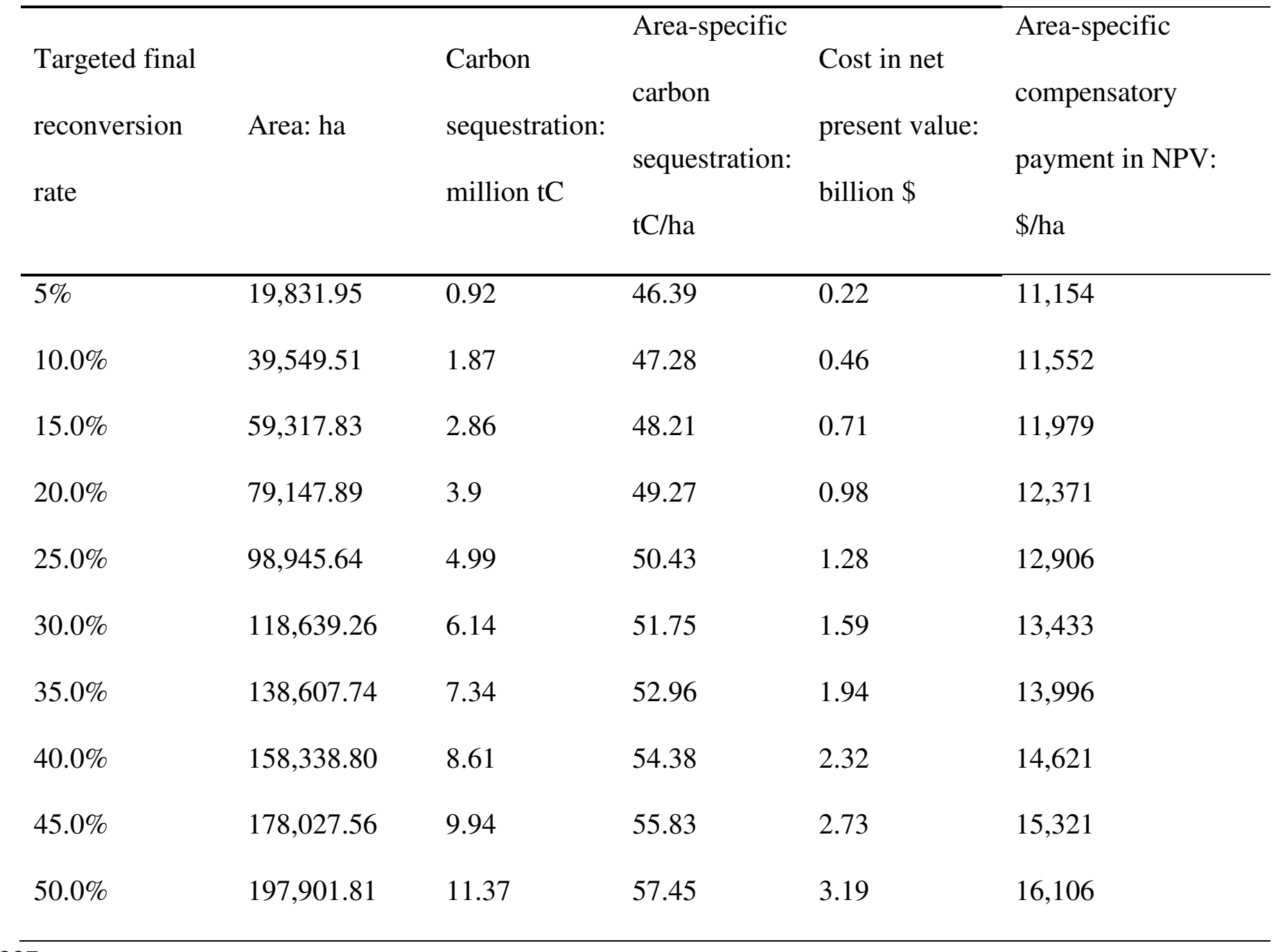

298 Discussion

299 Payments for ecosystem services (PES) had been considered as a panacea for achieving 300 conservation goals, although some people doubted its feasibility and effectiveness as PES would 301 no doubt increase the fiscal expenditure of the government (Smajgl et al., 2015). The combined 302 market and government payment system adopted in this study, however, splits PES into (1) the 303 economic benefit that rubber farmer earn from market-priced ecosystem services and (2) 304 compensation payments from the government. This combination of payments will effectively 
305 discourage local farmers from converting the newly established forests back into rubber

306 plantations and relieve the financial burden of local government.

\section{Reconversion dynamics}

According to the results predicted by the model, the projected reconversion rate is close to the expected reconversion rate. Although a random effect was involved, the variation is negligible, suggesting that the huge number of pixels ensures a simulated annual reconversion

311 rate close to the expected rate $\left(b_{i}\right)$ (Dubois and Prade, 2012). The annual reconversion area is the

312 highest in the first year and reduces smoothly thereafter due to the constant temporal reduction of 313 rubber plantations (i.e. an even-flow allocation of the annual reconversion rate), avoiding a sharp 314 increase in compensatory payments and reduce financial pressures exerted on local government 315 (Xie et al., 2016). The annual area-specific payments, on the contrary, increase annually because 316 the positive discount rate is applied for future payments (Zhang et al., 2015).

It should be noted that the production of rubber is assumed to be terminated after 37 years 318 of growth (Yi et al., 2014a), which bring down the economic benefit from rubber growing in the 319 artificial rainforest. However, other market-priced ecosystem services can compensate for the 320 decline of rubber production. It's also worth mentioning that rubber plantations at high altitudes 321 (> 900 m a.s.1.) were established during the rubber boom (2002-2014) in Xishuangbanna and 322 mostly in small patches or on the edge of big patches. Our schematic approach that reconverting 323 the edge stands primarily could remove the small patches and low productivity plantations over 324 time (Zhang et al., 2019), thus improved the connectivity of habitat effectively. 
327 rainforest will sequester less carbon than an established rubber plantation; therefore, we observe

328 an initial negative carbon sequestration benefit (Tang et al., 2003). However, because artificial

329 rainforests have a higher carbon storage potential (up to $180 \mathrm{tC} / \mathrm{ha}$ ) than rubber plantations $(\approx 90$

$330 \mathrm{tC} / \mathrm{ha})$, the difference is expected to become positive later in the growth of the artificial

331 rainforests (Tang et al., 2003; Xi, 2009; Yi et al., 2014b). We attribute the peak of carbon

332 sequestration benefit in 2037 to the age structure of rubber plantations in Xishuangbanna, $40 \%$ of

333 which were established between 1987 and 2012 (Beckschäfer, 2017). Those plantations will be

334 clear-cut in 2037, and in this analysis, the carbon removal is accounted for as the carbon benefit

335 of reconversion.

336 Sensitivity Analyses

337 Six factors (i.e., rubber price, rubber price variation, carbon price, traditional medicine

338 price, discount rate, and targeted final reconversion rate) were studied in the sensitivity analyses.

339 The rubber price was the most sensitive factor among all the prices of the products because the

340 payments are mainly determined by the profit difference in rubber production between rubber

341 plantations and artificial rainforests. Higher rubber prices give cause to a need for more

342 compensatory payments (Zhang et al., 2015). Variations in the rubber price increase the variation

343 in the compensatory payments, thereby also increasing the difficulty for local governments to

344 determine the appropriate level of compensation.

To analyze the effect of the carbon price, the price from the Korea Emissions Trading

346 Scheme was used as an upper limit, although some higher carbon prices $(\$ 403.37 / \mathrm{tC})$ were

347 proposed (Cramton et al., 2017). The increase in carbon price can reduce government payments

348 because the artificial rainforests have higher carbon sequestration potential than the rubber 
349 plantations. The traditional medicine price in this study will reduce with a high supply of

350 traditional medicine. If the price decreases to zero, the related decreases in economic benefit

351 from the artificial rainforests could bring about a need for higher compensatory payments from

352 the government.

A discount rate between $0 \%$ and $10 \%$ was recommended for an environmental project

354 (Sharp et al., 2016). A high discount rate will lead to a low NPV and a need for more

355 government payments in the future as compared with a low discount rate. In this study, to reduce

356 complexity in the calculation, the valuation of carbon sequestration shared the same discount rate

357 as the other merchandise in this study. Many scholars have argued that the discount rate of

358 carbon sequestration should be low to $1.4 \%$, because the investment for carbon sequestration

359 could reduce the risk of investment for the future (Stern, 2007). The low discount rate of carbon

360 sequestration can reduce compensatory payments due to the high carbon sequestration capacity

361 of artificial rainforests.

Changes to the targeted final reconversion rate, which we investigated from $5 \%$ to $50 \%$,

363 can increase both the NPVs of compensatory payments and the total benefits of carbon

364 sequestration by encouraging more reconversion of rubber plantations. The final reconversion

365 rate can also affect area-specific payment and carbon sequestration. More area-specific payments

366 and benefits of carbon sequestration occur in higher targeted final reconversion rate scenarios

367 due to more rubber plantations in lower land should be reconverted. As the targeted final

368 reconversion rate decreases, the decline in the annual reconversion area along projected period

369 slowed due to a more stable ratio of total plantations to edge plantation area. 
372 Degradation and Deforestation framework (REDD+). In this study, we estimated the

373 compensatory payments by integrating market-priced ecosystem services. The system could

374 potentially be used as a schematic approach of tropical cropland reconversion worldwide, such as

375 for rubber plantations, oil palms, coffee, and cocoa production. However, the prices of the

376 ecosystem services will fluctuate, and these changes are hardly predictable (Connor et al., 2015).

377 Unstable prices introduce uncertainty to the projection of any compensatory payment scheme.

We adopted logistic models to estimate carbon dynamics since the carbon sequestration

379 of rubber plantations and artificial rainforests is a critical ecosystem service. The simulation

380 could be improved by applying a process-based model, such as the Forest Vegetation Simulator

381 (Dixon, 2002) or TRIPLEX (Peng et al., 2002). Therefore, a process-based model should be

382 introduced and calibrated in future studies. Additionally, we only included $H$. brasiliensis, $R$.

383 verticillata, and $B$. ramiflora in the model because they are the three main species in the artificial

384 rainforest in which the most carbon is held (98\% biomass and 95\% NPP) (Tang et al., 2003).

385 Currently, it is impossible to include other species (mostly grass and shrub) in the model because

386 we do not have similarly detailed information, although these species also contribute to

387 ecosystem services.

Moreover, more market-priced ecosystem services should be involved in the

389 compensatory scheme in the future. In this study, we only considered natural rubber, fruit,

390 traditional medicine, and carbon sequestration to offset the profit from a rubber plantation. In the

391 future, more ecosystem services can be exchanged in the market, such as water flow regulation,

392 soil conservation, open-access recreation, and biodiversity (Bateman et al., 2013), which can

393 reduce the need for higher compensatory payments. By reconverting rubber plantations to 
394 artificial rainforests, local farmers may have more free time and can therefore increase their

395 income in the labor market. Therefore, it may be possible to reduce the government payment to a 396 more appropriate level after considering the local farmers' extra income in the future.

In general, monocultures can be characterized as having higher yields and lower costs to

398 establish and maintain. However, the market value of ecosystem services that can be derived

399 from an artificial rainforest is expected to offset some of their relatively higher cost after

400 replacing existing rubber monocultures. It should be noted that the artificial rainforest adopted in

401 this study represents a flexible and simplified model for rubber plantation reconversion, and an

402 alternative that combines the benefits of high carbon sequestration, high native plant diversity,

403 multilayer structure, among other economic and environmental benefits.

404 Conclusions

In this study, a combined market and government payment system was developed to

406 simulate the reconversion dynamics of forested rubber plantation as stimulated by economic

407 benefits. In the baseline simulation, the annual reconversion area reduced smoothly along the

408 projected period. Most of the small patches disappeared by 2050 due to restrictions of the edge-

409 first reconversion strategy. The projected compensatory payments accumulate annually, while

410 the incremental compensatory payments decrease. In the first decade, the carbon sequestration

411 benefit from reconversion is negative, but becomes positive in the following decades. Many

412 factors can affect the compensatory payment, including the rubber price, variations in the rubber

413 price, the carbon price, the targeted final reconversion rate, discount rate, and the traditional

414 medicine price. Variations in the rubber price, however, increase the uncertainty of the

415 compensatory payment. Rising carbon price and traditional medicine price, and decreasing the

416 rubber price and the final reconversion rate can lead to reduced payments. A high discount rate 
417 also reduces the NPV of these payments, though it would lead to increases in the annual

418 compensatory payment. The approach suggest in this study is likely transferable to other tropical

419 croplands if one aims to reconvert these lands.

420 Declarations

421 Ethics approval and consent to participate

$422 \quad$ Not applicable.

423 Consent for publication

$424 \quad$ Not applicable.

425 Availability of data and material

$426 \quad$ Not applicable.

427 Competing interests

$428 \quad$ The authors declare that they have no competing interests.

$429 \quad$ Funding

430 This research was funded by the Young Scientists Fund of the National Natural Science

431 Foundation of China (41901247), the CAS 135 program (2017XTBG-F03), the candidates of the

432 Young and Middle-Aged Academic Leaders of Yunnan Province (2019HB040), the Yunnan Ten

433 Thousand Plan Young \& Elite Talents Project, China postdoc foundation grant \#2017M613021,

434 Yunnan Province Government for Talents Program, and the CAS "Light of West China”

435 Program, and Lancang-Mekong Cooperation Special Fund.

436 Authors' contributions 
Weiguo Liu and Liang Song conceived the idea and designed the study. Jiaqi Zhang and

438 Philip Beckschäfer analyzed the GIS datasets. Weiguo Liu and Yan Yan wrote the necessary

439 codes. Weiguo Liu and Liang Song led the writing of the manuscript with substantial

440 contributions from all co-authors. Christoph Kleinn, Gbadamassi G.O. Dossa provided

441 innovative suggestions to improve the payment system and this manuscript. Jianjun Huai ensured

442 the necessary corrections on the economic aspect. All authors gave final approval for

443 publication.

444 Acknowledgments

445 The authors want to thank Dr. Richard T. Corlett for his support and inspiring the idea

446 behind this study.

447 Availability of data and materials

$448 \quad$ Not applicable

449

450 References

451 Ahlheim, M., Börger, T., Frör, O. 2015. Replacing rubber plantations by rain forest in Southwest

452 China — who would gain and how much? Environmental monitoring and assessment, 187(2): 3.

453 Alhassan, M., Motallebi, M., Song, B. 2019. South Carolina forestland owners' willingness to 454 accept compensations for carbon sequestration. Forest Ecosystems, 6(1): 16.

455 Balsiger, J., Bahdon, J., Whiteman, A. 2000. The utilization, processing and demand for 456 rubberwood as a source of wood supply. Rome: Forestry Policy and Planning Division. 
Bateman, I.J., Harwood, A.R., Mace, G.M., Watson, R.T., Abson, D.J., Andrews, B., Binner, A., Crowe, A., Day, B.H., Dugdale, S., Fezzi, C., Foden, J., Hadley, D., Haines-Young, R., Hulme, M., Kontoleon, A., Lovett, A.A., Munday, P., Pascual, U., Paterson, J., Perino, G., Sen, A., Siriwardena, G., Soest, D.V., Termansen, M. 2013. Bringing ecosystem services into economic decision-making: land use in the United Kingdom. Science, 341(6141): 45-50.

Beckschäfer, P. 2017. Obtaining rubber plantation age information from very dense Landsat TM \& ETM+ time series data and pixel-based image compositing. Remote Sensing of Environment, 196: 89-100.

Bryan, B.A., Ye, Y. Connor, J.D. 2018. Land-use change impacts on ecosystem services value: Incorporating the scarcity effects of supply and demand dynamics. Ecosystem services, 32: $144-157$.

Chen, H., Yi, Z., Schmidt-Vogt, D., Ahrends, A., Beckschäfer, P., Kleinn, C., Ranjitkar, S. Xu, J. 2016. Pushing the limits: The pattern and dynamics of rubber monoculture expansion in Xishuangbanna, SW China. PloS one, 11(2).

Connor, J.D., Bryan, B.A., Nolan, M., Stock, F., Gao, L., Dunstall, S., Graham, P., Ernst, A., Newth, D., Grundy, M., Hatfield-Dodds, S. 2015. Modelling Australian land use competition and ecosystem services with food price feedbacks at high spatial resolution. Environmental Modelling \& Software, 69: 141-154.

Cramton, P., MacKay, D. J., Ockenfels, A., Stoft, S., Cooper, R. N., Gollier, C. 2017. Global carbon pricing: the path to climate cooperation. The MIT Press. 
477 Deng, Y., Tang, Y., Cao, M., Zhang, Y., Liu, W., Deng, X., Li, Y., Zhang, W. 2012. Community

478 structure and throughfall erosivity characters of artificial rainforest in Xishuangbanna. Acta

479 Ecologica Sinica, 32(24): 7836-7843. (in Chinese with English abstract)

480 Dixon G.E. 2002. Essential FVS: A user's guide to the Forest Vegetation Simulator. Fort

481 Collins, CO: USDA-Forest Service, Forest Management Service Center.

482 Dubois, D., Prade, H. 2012. Possibility theory: an approach to computerized processing of

483 uncertainty. Springer Science \& Business Media.

484 FRED Federal Reserve Economic Data. Global price of rubber.

485 https://fred.stlouisfed.org/series/PRUBBUSDM. (Accessed on Feb. 2nd, 2020)

$486 \mathrm{Hu}, \mathrm{H}$. , Liu, W. and Cao, M. 2008. Impact of land use and land cover changes on ecosystem

487 services in Menglun, Xishuangbanna, Southwest China. Environmental monitoring and

488 assessment, 146(1-3): 147-156.

489 ICAP. 2019. Emissions trading worldwide - status report 2019. Berlin, Germany.

490 Lan, G., Li, Y. Jatoi, M.T., Tan, Z., Wu, Z., Xie, G. 2017. Change in soil microbial community

491 compositions and diversity following the conversion of tropical forest to rubber plantations in

492 Xishuangbanan, Southwest China. Tropical Conservation Science, 10: 1940082917733230.

493 Li, H., MA, Y., Guo, Z., Liu, W. 2007. Land use/land cover dynamic change in Xishuangbanna

494 based on RS and GIS technology. Journal of Mountain Science, 3. (in Chinese with English

495 abstract). 
Liu, W., Duan, W. 1997. Analysis of microclimatic effect of tropical artificial rainforest. Journal of Yunnan Tropical Crops Science \& Technology, 20(3): 7-11. (in Chinese with English abstract)

Liu, W., Li, H. 1997. Laws of temperature variation of artificial rainforest soil in Xishuangbanna. Journal of Yunnan Tropical Crops Science \& Technology, 20(1): 16-20. (in Chinese with English abstract)

Liu, W., Li, J., Lu, H., Wang, P., Luo, Q., Liu, W., Li, H. 2014. Vertical patterns of soil water acquisition by non-native rubber trees (Hevea brasiliensis) in Xishuangbanna, southwest China. Ecohydrology, 7: 1234-1244.

Luo, P., Zhou, J., Chen, M., Xu, J., Lu, C., Huang, L., Deng, X. 2014. Baccaurea seed resource inventory and cultivar selection in Guangxi. China Southern Fruit Tree, 43(6): 82-84. (in Chinese)

Meng, G., Zhang, L. 2008. Characteristics of Climate Change in Recent 45 Years in Xishuanbanna. Meteorological Science and Technology, 36(4): 410-413.

Min, S., Waibel, H., Cadisch, G., Langenberger, G., Bai, J., Huang, J. 2017. The economics of smallholder rubber farming in a mountainous region of southwest China: Elevation, ethnicity, and risk. Mountain Research and Development, 37(3): 281-293.

Pei, S. 2010. The Road to the Future? The Biocultural Values of the Holy Hill Forests of Yunnan Province, China. In Sacred Natural Sites: Conserving Nature and Culture. Edited by Bas Verschuuren. Abingdon-on-Thames: Routledge: 98-106. 
516 Peng, C., Liu, J., Dang, Q., Apps, M.J., Jiang, H. 2002. TRIPLEX: a generic hybrid model for 517 predicting forest growth and carbon and nitrogen dynamics. Ecological Modelling, 153(1-2): $518 \quad 109-130$.

519 Sarathchandra, C., Dossa, G.G.O., Ranjiktar, N.B., Chen, H., Zhai, D., Ranjitkar, S., De Silva, 520 K.H.W.L., Wickramasinghe, S., Xu, J., Harrison, R.D. 2018. Effectiveness of protected areas 521 in preventing rubber expansion and land conversion in Xishuangbanna, Southwest China. Land 522 Degradation and Development. 29(8): 2417-2427.

523 Seymour F, Harris N.L. 2019. Reducing tropical deforestation. Science, 365: 756-757.

524 Sharp, R., Tallis, H.T., Ricketts, T., Guerry, A.D., Wood, S.A., Chaplin-Kramer, R., Nelson, E., 525 Ennaanay, D., Wolny, S. Olwero, N., 2016. InVEST User Guide.

526 Smajgl, A., Xu, J., Egan, S., Yi, Z. F., Ward, J., Su, Y. 2015. Assessing the effectiveness of 527 payments for ecosystem services for diversifying rubber in Yunnan, China. Environmental 528 Modelling \& Software, 69: 187-195.

529 Song, Q., Zhang, Y. 2010. Biomass, carbon sequestration and its potential of rubber plantations 530 in Xishuangbanna, southwest China. Chinese Journal of Ecology, 29(10): 1887-1891. (in 531 Chinese with English abstract)

532 Stevanovic, M., Popp, A., Bodirsky, B. L., Humpenöder, F., Müller, C., Weindl, I., Philipp 533 Dietrich, J., Lotze-Campen, H., Kreidenweis, U., Rolinski, S., Biewald, A. Wang, X. 2017. 534 Mitigation strategies for greenhouse gas emissions from agriculture and land-use change: 535 consequences for food prices. Environmental Science \& Technology, 51(1): 365-374. 
536 Tan, Z., Zhang, Y., Song, Q., Liu, W., Deng, X., Tang, J., Deng, Y., Zhou, W., Yang, L., Yu, G.

537 Sun, X. 2011. Rubber plantations act as water pumps in tropical China. Geophysical Research

$538 \quad$ Letters, 38(24): L24406.

539 Tang, J., Zhang, J., Song, Q., Huang, Z., Li, Z., Wang, L., Zeng, R. 2003. Biomass and net

540 primary productivity of artificial tropical rainforest in Xishuangbanna. Chinese Journal of

541 Applied Ecology, 14(1): 1-6. (in Chinese with English abstract)

542 Warren-Thomas, E.M., Edwards, D.P., Bebber, D.P., Chhang, P., Diment, A.N., Evans, T.D.,

543 Lambrick, F.H., Maxwell, J.F., Nut, M., O’Kelly, H.J. and Theilade, I. 2018. Protecting

544 tropical forests from the rapid expansion of rubber using carbon payments. Nature

$545 \quad$ Communications, 9(1): 911.

$546 \mathrm{Xi}$, J. 2009. Valuation of ecosystem services in Xishuangbanna biodiversity conservation

547 corridors initiative pilot site, China. Greater Mekong subregion core environment program.

548 Xie, C., Wang, J., Peng, W., Zhang, K., Liu, J., Yu, B., Jiang, X. 2016. The new round of CCFP:

549 policy improvement and implementation wisdom. Forest Economics, 3: 43-52. (in Chinese

$550 \quad$ with English abstract)

551 Yang, X., Blagodatsky, S., Lippe, M., Liu, F., Hammond, J., Xu, J., Cadisch, G. 2016. Land-use

552 change impact on time-averaged carbon balances: rubber expansion and reforestation in a

553 biosphere reserve, South-West China. Forest Ecology and Management, 372: 149-163.

554 Yi, Z., Cannon, C. H., Chen, J., Ye, C. X., Swetnam, R.D. 2014a. Developing indicators of 555 economic value and biodiversity loss for rubber plantations in Xishuangbanna, southwest

556 China: A case study from Menglun township. Ecological Indicators, 36: 788-797. 
557 Yi, Z., Wong, G., Cannon, C.H., Xu, J., Beckschäfer, P., Swetnam, R.D. 2014b. Can carbon558 trading schemes help to protect China's most diverse forest ecosystems? A case study from 559 Xishuangbanna, Yunnan. Land Use Policy, 38: 646-656.

560 Zhai, D., Dong, J., Cadisch, G., Wang, M., Kou, W., Xu, J., Xiao, X., Abbas, S. 2018.

561 Comparison of pixel-and object-based approaches in phenology-based rubber plantation 562 mapping in fragmented landscapes. Remote Sensing, 10(1): 44.

563 Zhang, J., Chang, S., Wee, A., Xue, D. 2015. Study on economic compensation standard for the 564 conversion of rubber plantation to rainforest in Mandan Village, Xishuangbanna. Resources 565 Science, 37(12): 2461-2470.

566 Zhang, J., Cao, M. 1995. Tropical forest vegetation of Xishuangbanna, SW China and its 567 secondary changes, with special reference to some problems in local nature conservation. 568 Biological Conservation, 73(3): 229-238.

569 Zhang, J., Corlett, R. T., Zhai, D. 2019. After the rubber boom: good news and bad news for 570 biodiversity in Xishuangbanna, Yunnan, China. Regional Environmental Change, 19(6): 1713$571 \quad 1724$. 
573 Table 1. Definition of the baseline and sensitivity analyses

574 Table 2. Annual reconversion area (ha) and cumulative percentage from 2021 to 2050

575 Table 3. Effect of the different factors on rubber plantation reconversion

576 Table 4. Simulations for different targeted final reconversion rate 


\section{$577 \quad$ Figure Captions:}

578 Fig. 1. The location of Xishuangbanna

579 Fig. 2. The framework of the combined market and government payment system

580 Fig. 3. The reconversion dynamic in years a) 2020, b) 2030, c) 2040, and d) 2050

581 Fig. 4. Annual compensatory payment increments in the projected period, 2021-2050

582 Fig. 5. Annual carbon sequestration in the baseline within the projected period, 2012-2050

583 Fig. 6. Sensitivity analyses of compensatory payments on a) rubber price, b) carbon price, c)

584 discount rate and d) traditional medicine price 


\section{Figures}

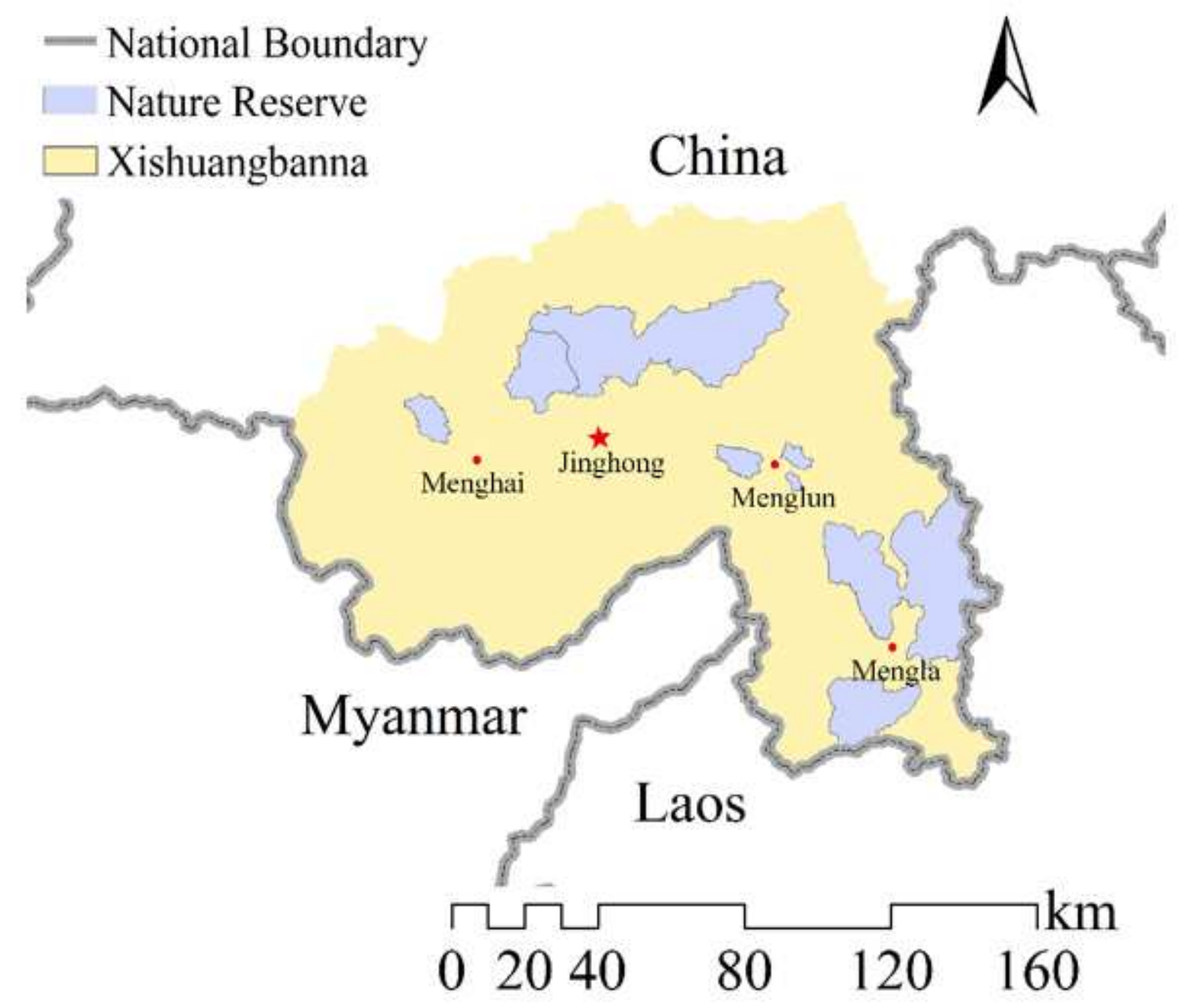

Figure 1

The location of Xishuangbanna Note: The designations employed and the presentation of the material on this map do not imply the expression of any opinion whatsoever on the part of Research Square concerning the legal status of any country, territory, city or area or of its authorities, or concerning the delimitation of its frontiers or boundaries. This map has been provided by the authors. 


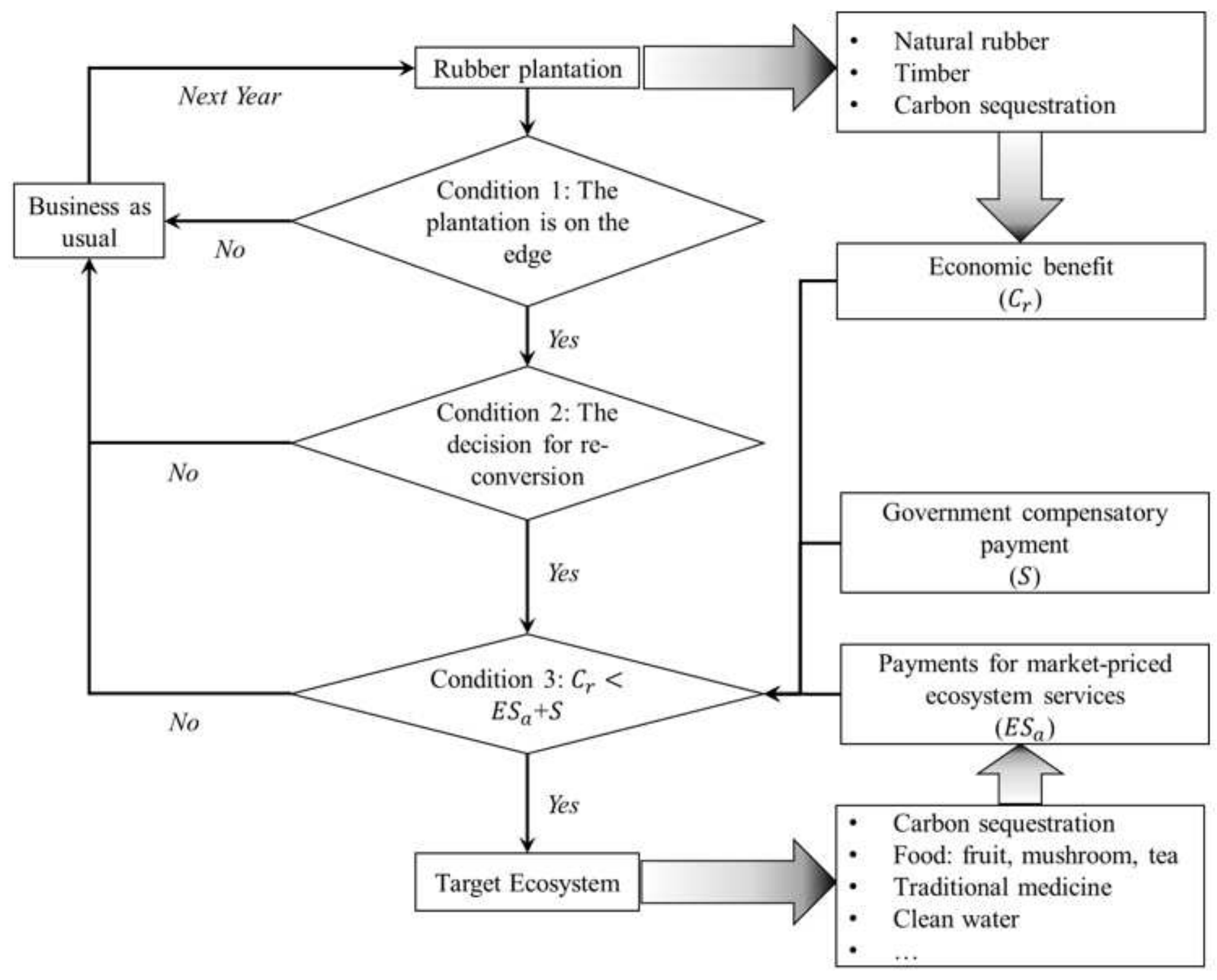

Figure 2

The framework of the combined market and government payment system 

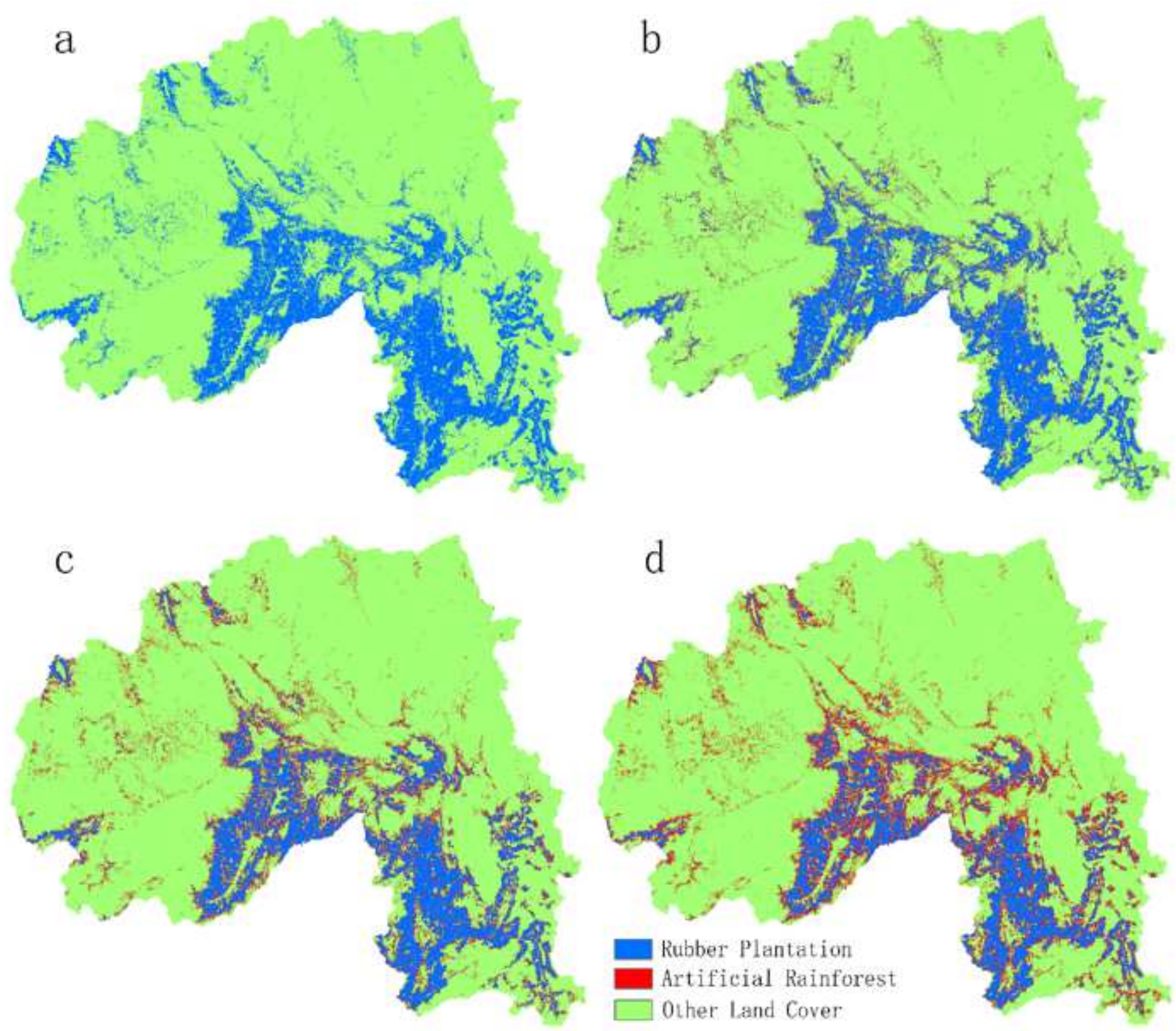

Figure 3

The reconversion dynamic in years a) 2020, b) 2030, c) 2040, and d) 2050 Note: The designations employed and the presentation of the material on this map do not imply the expression of any opinion whatsoever on the part of Research Square concerning the legal status of any country, territory, city or area or of its authorities, or concerning the delimitation of its frontiers or boundaries. This map has been provided by the authors. 


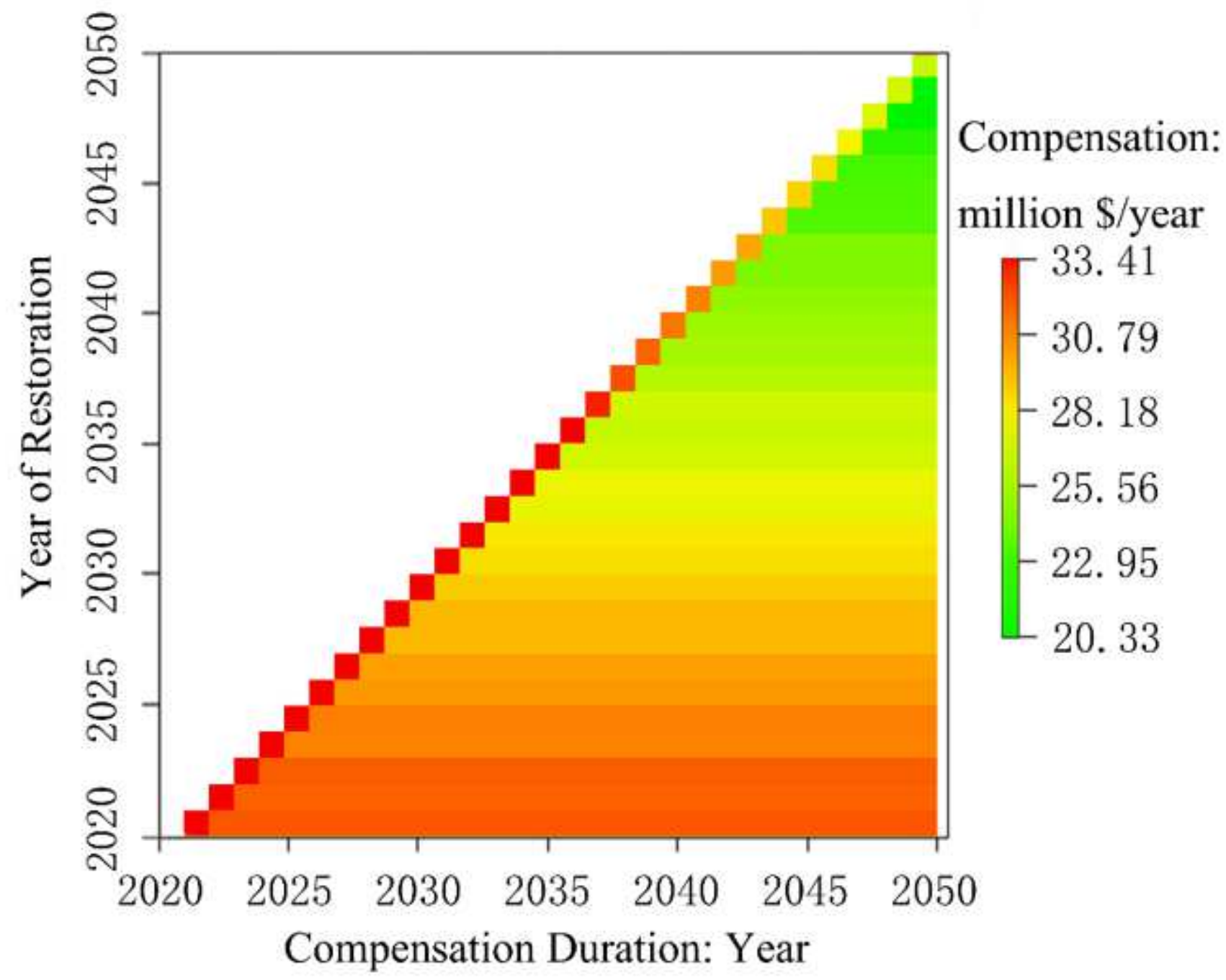

Figure 4

Annual compensatory payment increments in the projected period, 2021-2050 


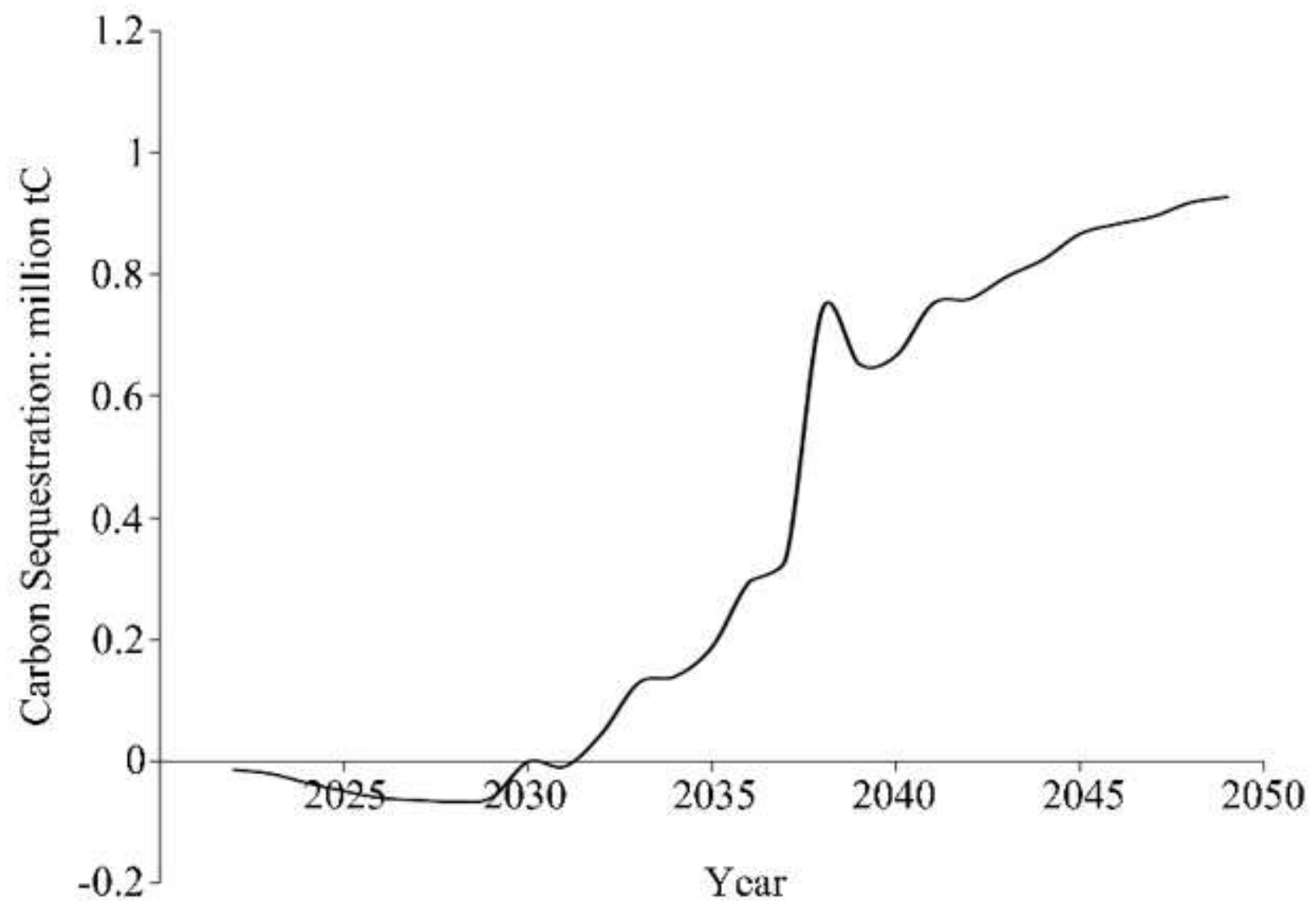

Figure 5

Annual carbon sequestration in the baseline within the projected period, 2012-2050 

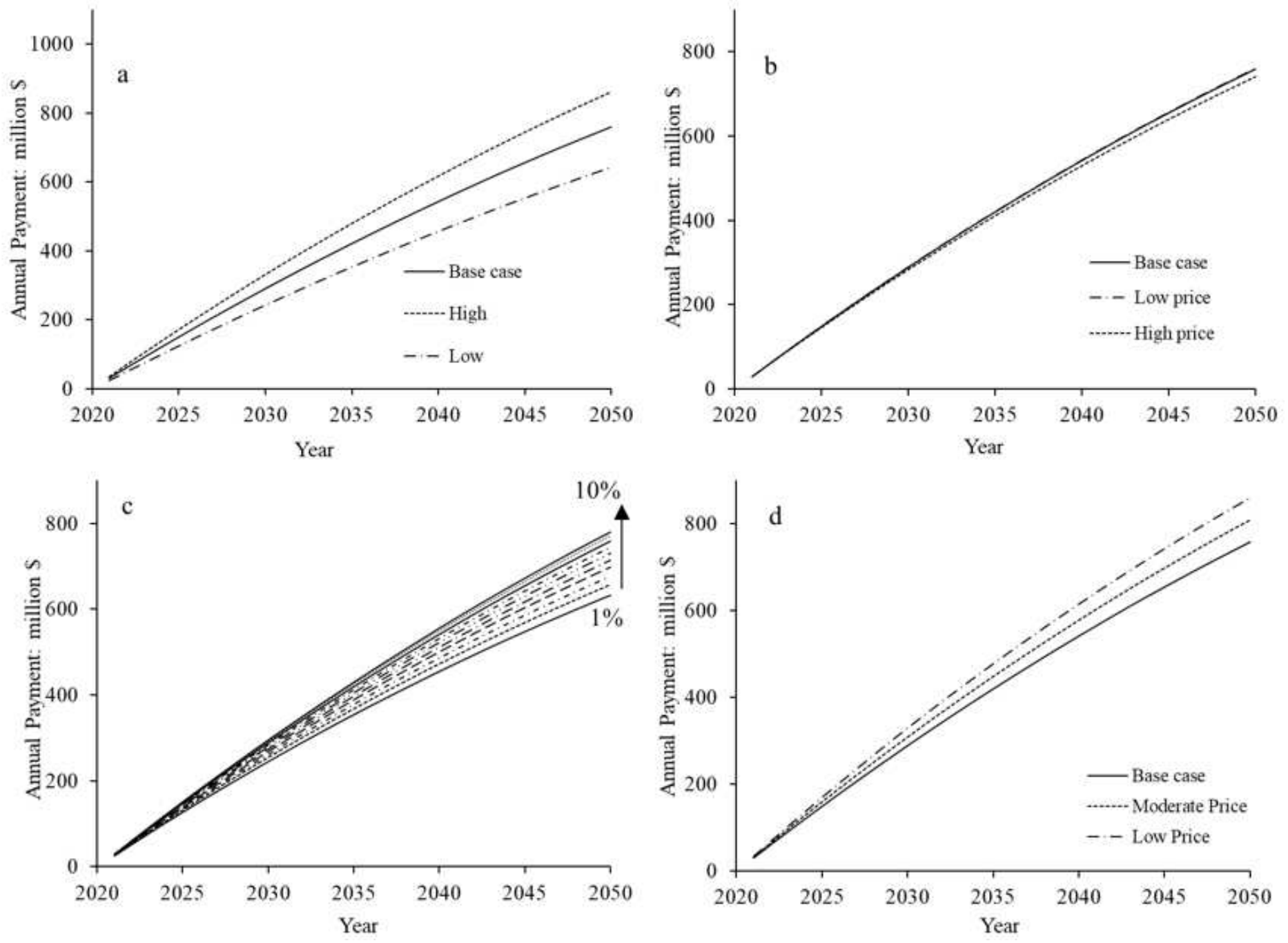

\section{Figure 6}

Sensitivity analyses of compensatory payments on a) rubber price, b) carbon price, c) discount rate and d) traditional medicine price 